\title{
Yürüme analizi: hasta değerlendirmesi ve hazırlığı
}

\author{
Gait analysis: patient evaluation and preparation
}

\author{
Yasemin Kala, Hüseyin Bol
}

Türkiye Spastik Çocuklar Vakfı, Hareket Analiz Birimi, İstanbul

\begin{abstract}
Yürüme bir yerden bir yere gidebilmek amacıyla gövdenin ilerletilmesidir. Uzun süre yorulmadan yürüyebilmek için beyin, omurilik, periferik sinirler, kaslar, kemik ve eklemler birlikte çalışmalı, eklem hareketleri, kasılmanın zamanı ve gücü yeterli olmalıdır. Normal yürümenin karmaşıklığı ve çıplak gözle değerlendirmenin güçlüğünden dolayı, yürüme zorluklarının tespiti için modern yürüme analizi sistemleri geliştirilmiştir. Günümüzde modern analizler, hareket analiz laboratuvarlarında gerçekleştirilmektedir. Bireye yürüme analizi yapılabilmesi için hastanın, detayIı anamnez alımı, klinik değerlendirme, video analiz ve kinematik-kinetik analiz aşamalarından geçmesi gereklidir. Bu aşamalar sonucunda elde edilen veriler bilgisayarda geliştirilmiş yazılımlar ile işlenir. Tüm bu işlemler sonucu yürüme siklusu boyunca frontal-sagittal ve transvers düzlemlerde vücut segmentlerinin grafiksel olarak değerleri elde edilir.
\end{abstract}

Anahtar sözcülkler: yürüyüş; üç-boyutlu; yürüme analizi; hasta değerlendirme; hasta hazırlığl; işaretleyici; yürüme

Y ürüme bir yerden bir yere gidebilmek amacıyla gövdenin ilerletilmesidir. İki ayak üzerinde dik yürüme yalnızca insana özgü bir beceridir. Yaşamın çok basit bir parçası gibi görünmekle birlikte aslında son derece karmaşık bir hareketler zinciridir. Uzun süre yorulmadan yürüyebilmek için beyin, omurilik, periferik sinirler, kaslar, kemik ve eklemler birlikte çalışmalı, eklem hareketleri, kasılmanın zamanı ve gücü yeterli olmalıdır. ${ }^{[1-3]}$

Normal yürümenin karmaşıklığı ve çıplak gözle değerlendirilmesinin güçlüğü bilim adamlarını ayrıntılı ve güvenilir inceleme yöntemleri geliştirmeye itmiştir. Modern yürüme analizi yürümenin sayısal olarak değerlendirilmesi, tanımlanması ve yorumlanmasıdır. Her ne kadar deneyimli uzmanlar yürümeyi gözle
Gait is the motion of trunk for stepping from one place to another. In order to walk for a long time without getting tired; brain, spinal cord, peripheral nerves, muscles, bones and joints must work together, joint movements, time and strength of contraction should be sufficient. Due to the complexity of regular walking and the difficulties of evaluation with naked eye, modern gait analysis systems have been developed for assessment of walking difficulties. Recently, modern analysis is carried out via motion analysis laboratories. In order to make gait analysis of the individuals, detailed anamnesis form must be filled, clinical evaluation, video analysis and kinematic-kinetic analysis must be performed. All results must be evaluated with the software developed for this purpose. As a result of all these operations, graphical data obtained from the frontal-sagittal and transverse planes of the body segment during gait cycle is evaluated.

Key words: gait; three dimensional; gait analysis; patient preparation; patient evaluation; marker; walk

- İletişim adresi: Yasemin Kala, Türkiye Spastik Çocuklar Vakfi, Hareket Analizi Birimi, Prof. Dr. Hıfzi Özcan Cad. No:8 Ataşehir, İstanbul Tel: 0537 -0113288 e-posta: yaseminkala@tscv.org.tr

- Gelis tarihi: 23 Temmuz 2014 Kabul tarihi: 23 Temmuz 2014 
Günümüzde modern analizler, hareket analiz laboratuvarlarında gerçekleştirilmektedir ve hastaya yürüme analizi yapılabilmesi için şu aşamalardan geçilmelidir.

Illk aşamada hasta yürüme analizi için başvurur ve yürüme analizi, yapılacak değerlendirmeler ve süresi hakkında bilgilendirilir. Randevu tarihinde ilk işlem olarak hastadan ayrıntılı anamnez alınır (Şekil 1). Anamnez içeriğinde; hastanın özgeçmişi (doğum tarihi, cinsiyeti, boyu, kilosu, prenatal-natal ve postnatal doğum hikayesi), soygeçmişi, eskiden geçirmiş olduğu operasyonların kayıtları (operasyonların adı,

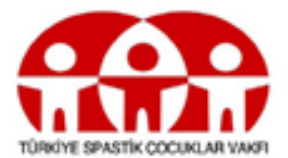

Ad- Soyad:

Doğum Tarihi:

Cinsiyet:

Boy:

Kilo:

GMFMc:

HİKAYE:

\section{PRENETAL:}

Akraba evliliği

Sigara

Düşük

NATAL:

Normal doğum

POSNATAL:

Doğum ağırlığı

\section{NEONATAL:}

Menenjit

Malnutrisyon

\section{CERRAHI:}

Operasyon Tarihi
T.S.C.V

METIN SABANCI

ÖZEL EĞITTMM VE REHABILLITASYON MERKEZİ

HAREKET ANALIZI LABORATUVARI ANAMNEZ FORMU

$\mathrm{K} 1 \mathrm{Z}$

Erkek

MACS:
Tarih:

Tel:

Adres:

Yönlendiren:

\section{Stres \\ Gebelik Sayısı \\ D.S Ölüm}

Zor doğum

Gecikmiş ağlaması

Sarılik

Beslenme zor.

Alkol

Kürtaj

Sezeryan

İlk 2 y1l içinde travma

Hipoglisemi

Epilepsi

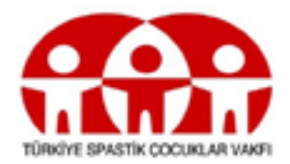

Travma

İlaç Kullanımı

Hamilelik arası süre

Asfiksi

Epidural

Hidrosefali

Ment.Ret.

Mikrosefali

İlaç

\section{FİİK TEDAVİ:}

Mevcut durum:

Yardımcı cihaz kulanımı:

Takip edilen kurum - sıklığı:

Takip eden uzman:

Şekil 1. Hasta anamnez formunun ayrıntılı görünümü. 
yeri, zamanı, kimin tarafından yapıldığı gibi), mevcut fiziksel durumu, yardımcı cihaz kullanımı, herhangi bir kurum tarafından takip edilip edilmediği, hangi kurum ve uzman tarafından, hangi sıklıkla takip edildiği ve yürüme analizi için kimin yönlendirdiği gibi bilgiler sisteme işlenir. Bu aşama hastanın tanınmasını, mevcut sisteme (veri tabanına) dahil edilmesini ve bu sayede gelecekte ihtiyaç duyulduğunda sağlıklı takibinin yapılmasını sağlar.

İkinci aşama klinik muayenedir (Şekil 2). Klinik (fiziksel) muayene ile postür analizi, eklem hareket genişlikleri (goniometrik ölçümler), spastisite, GMFCS

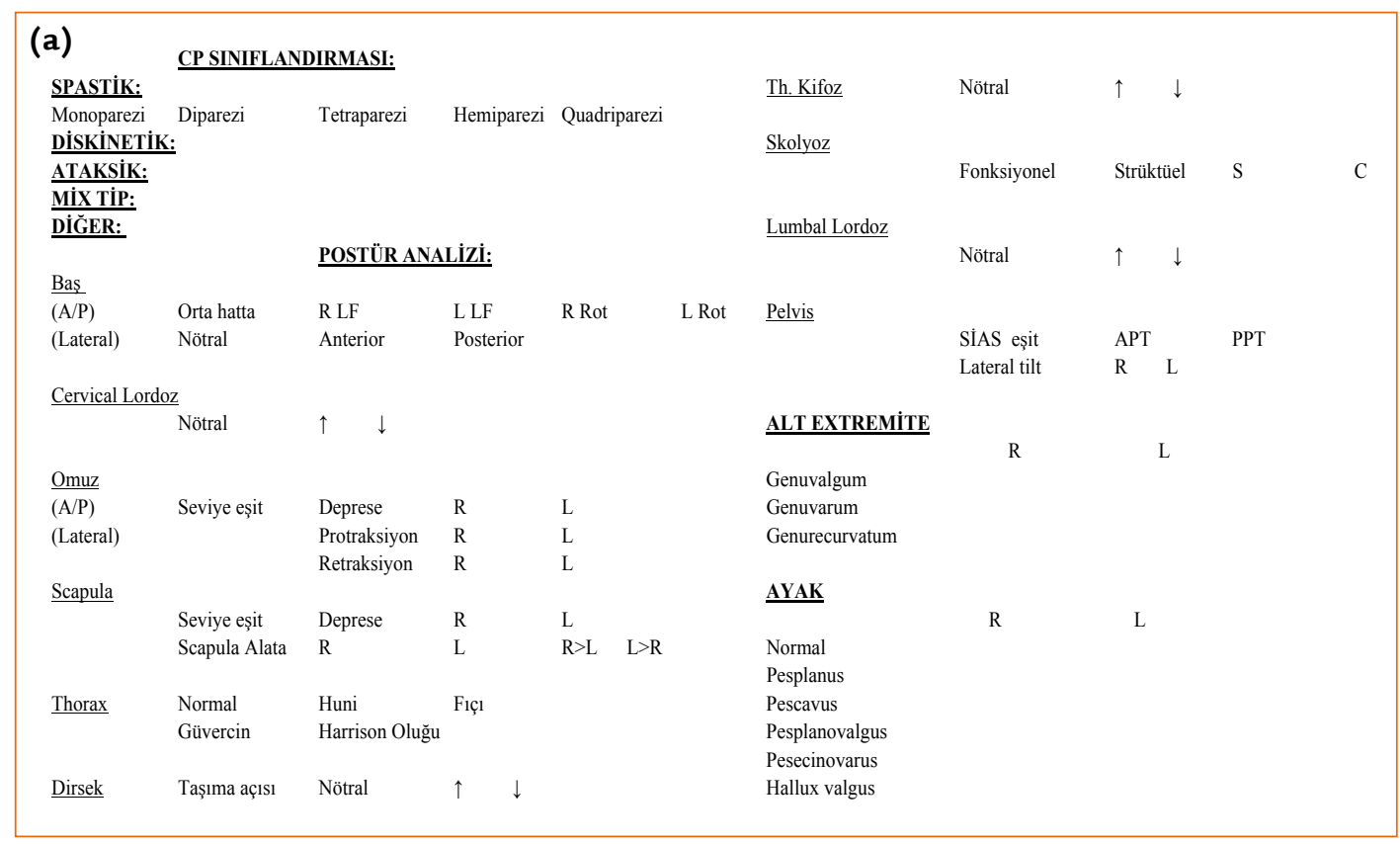

\begin{tabular}{|c|c|c|c|c|c|c|c|c|c|c|}
\hline \multicolumn{11}{|l|}{ (b) } \\
\hline \multicolumn{5}{|l|}{ ROM } & \multicolumn{3}{|l|}{ SPASTISITE } & \multicolumn{3}{|l|}{ KAS GÜCÜ } \\
\hline KALÇA & $\mathrm{R}$ & $\mathrm{R}$ & $\mathrm{L}$ & $\mathrm{L}$ & KALÇA & $\mathrm{R}$ & $\mathrm{L}$ & KALÇA & $\mathrm{R}$ & $\mathrm{L}$ \\
\hline Flexion & & & & & Fleksor & & & Extansion & & \\
\hline Extansion & & & & & Extansor & & & Flexsion & & \\
\hline Thomas Testi & & & & & Add. Kalça 0' - Diz 0' & & & Adduksion & & \\
\hline \begin{tabular}{|l} 
Add. Kalça 0'-DizO' \\
\end{tabular} & & & & & Add. Kalça 0' - Diz 90' & & & Abduksion & & \\
\hline \begin{tabular}{|l} 
Add . Kalça 0'-Diz90' \\
\end{tabular} & & & & & Abduktor & & & int. Rot. & & \\
\hline Abduktion & & & & & internal Rot & & & Ext. Rot. & & \\
\hline Femoral Anteversion & & & & & Eksternal Rot & & & & & \\
\hline Int. Rot. - prone & & & & & Phelps Testi & & & & & \\
\hline \multicolumn{11}{|l|}{ int. Rot. - oturma } \\
\hline \multicolumn{11}{|l|}{ Ext. Rot - prone } \\
\hline \multicolumn{11}{|l|}{ Ext. Rot - oturma } \\
\hline Diz & & & & & Diz & & & Diz & & \\
\hline Extansion & & & & & Duncan-ELY & & & Extansion & & \\
\hline Flexion & & & & & Rectus Femoris uzunluğu & & & Flexion & & \\
\hline \begin{tabular}{|l|} 
Popliteal A. Uni/Bilat. \\
\end{tabular} & & & & & Hamstring & & & Düz bacak kaldırma & & \\
\hline Tibio-Femorel Açı & & & & & Patella Alta & & & & & \\
\hline \multicolumn{11}{|l|}{\begin{tabular}{|l|} 
Duncan-ELY Testi \\
\end{tabular}} \\
\hline AYAK BiLEĞi & & & & & AYAK BİLEĞi & & & AYAK BILLEĞi & & \\
\hline \begin{tabular}{|l|} 
Dorsi flexion - Diz 90' \\
\end{tabular} & & & & & Plantar flexion - Diz 90' & & & Dorsi flexion & & \\
\hline Dorsi flexion - Diz 0' & & & & & Plantar flexion - Diz 0' & & & Plantar flexion & & \\
\hline Plantar Flexion & & & & & Tibialis Post. & & & inversion & & \\
\hline inversion & & & & & Klonus & & & Eversion & & \\
\hline Eversion & & & & & ÇAP ÖLÇÜMLERI & & & GÖVDE & & \\
\hline Silver Skiold Testi & & & & & Ayak genişliği & & & Abdominaller & & \\
\hline Bimalleolar Aks & & & & & Ayak bileği çapı & & & Sırt Kasları & & \\
\hline Thigh-Foot Ang. & & & & & Ayak uzunluğu & & & & & \\
\hline Hind/Forefoot Ang. & & & & & Diz çapı & & & & & \\
\hline
\end{tabular}

Şekil 2. a, b. Hasta klinik değerlendirme formunun ayrıntılı görünümü. 
(Gross Motor Functional Classification System) skoru, MACS (Manual Ability Classification System) skoru, eklem ve kas kontraktürleri, kas kuvvet ve tonusları, kemik deformite, uzunluk ölçümü, çevre ve çap ölçümleri, gerekli ortopedik testler ve nörolojik durum değerlendirilir. Klinik değerlendirme, yürüme analizindeki markerlama ya da kalibrasyon vb. işlemlerden kaynaklanabilecek hata ihtimalini minimale indirgemek için son derece önemlidir. Gerekirse tüm işlem tekrarlanabilmektedir.

Üçüncü aşama olarak, video analiz yapılır. Hastanın zeminle aynı düzeyde fakat farklı renkle belirlenmiş olan 5-6 metrelik yürüme yolunda eklemlerinin görülmesini engellemeyecek bir kıyafetle (şort ya da mayo gibi) yürümesi sırasında; 5 metre uzaklıkta önden (frontal düzlem) ve 3 metre uzaklıkta yandan (sagittal düzlem) kısa süreli video çekimleri alınarak bilgisayar ortamına aktarılır (Şekil 3). Daha sonra bilgisayarda hastanın önden ve yandan çekimleri eşzamanlı olarak izlenir, yürüme sırasındaki hareketler yavaşlatılıp ayrıntılı incelenir. Bu, hastanın yürüyüşündeki birincil anormallikleri görmemizi sağlar; ayrıca, problemin nereden kaynaklanıyor olabileceğine dair fikir verir, problem kaynağı olarak odaklanmamız ya da klinik muayenemizde daha ayrıntılı incelememiz gereken yerler hakkında bizi yönlendirir. ${ }^{[4]}$

Dördüncü aşama hastanın kinematik ve kinetik analizlerin yapılabilmesi için hastayı yürüme analizi sistemine hazırladığımız aşamadır. Bu aşamada amaç, normal (rutin-günlük) yürüme siklusu boyunca vücut segmentlerinin sürekli değişen eklem açılarını ve kuvvet platformu (force plate) aracılığı ile ayak bileği, diz ve kalça eklemine etki eden momentler ve eklemlerde oluşan güçleri yürüme analizi sistemine kaydedebilmek için belirli bir model oluşturmaktır. Modelleme için genellikle Modifiye Helen Hayes modeli kullanılır (Şekil 4). Bu modelde hastaya anatomik pozisyonda duruşta Helen Heyes tarafindan tanımlanmış olan 29 farklı anatomik noktada (1. marker, frontal bölgede alın ortasına; 2. marker, paryetel bölgede baş tepe noktasına; 3. marker, oksipital bölge orta noktasına; 4. ve 5 . marker, sağ ve sol omuz klavikula akromiyal ekleme; 6. marker, sağ skapula ortasına; 7. ve 8. marker, sağ ve sol dirsek lateral epikondiline; 9. ve 10. marker, el bileği ortasına; 11. ve 12. marker, spina iliaka anterior superiora; 13 . marker, sakruma; 14 . ve 15 . marker, femur laterali orta noktasına; 16. ve 17. marker, lateralde diz orta noktasına; 18. ve 19. marker, lateralde tibia

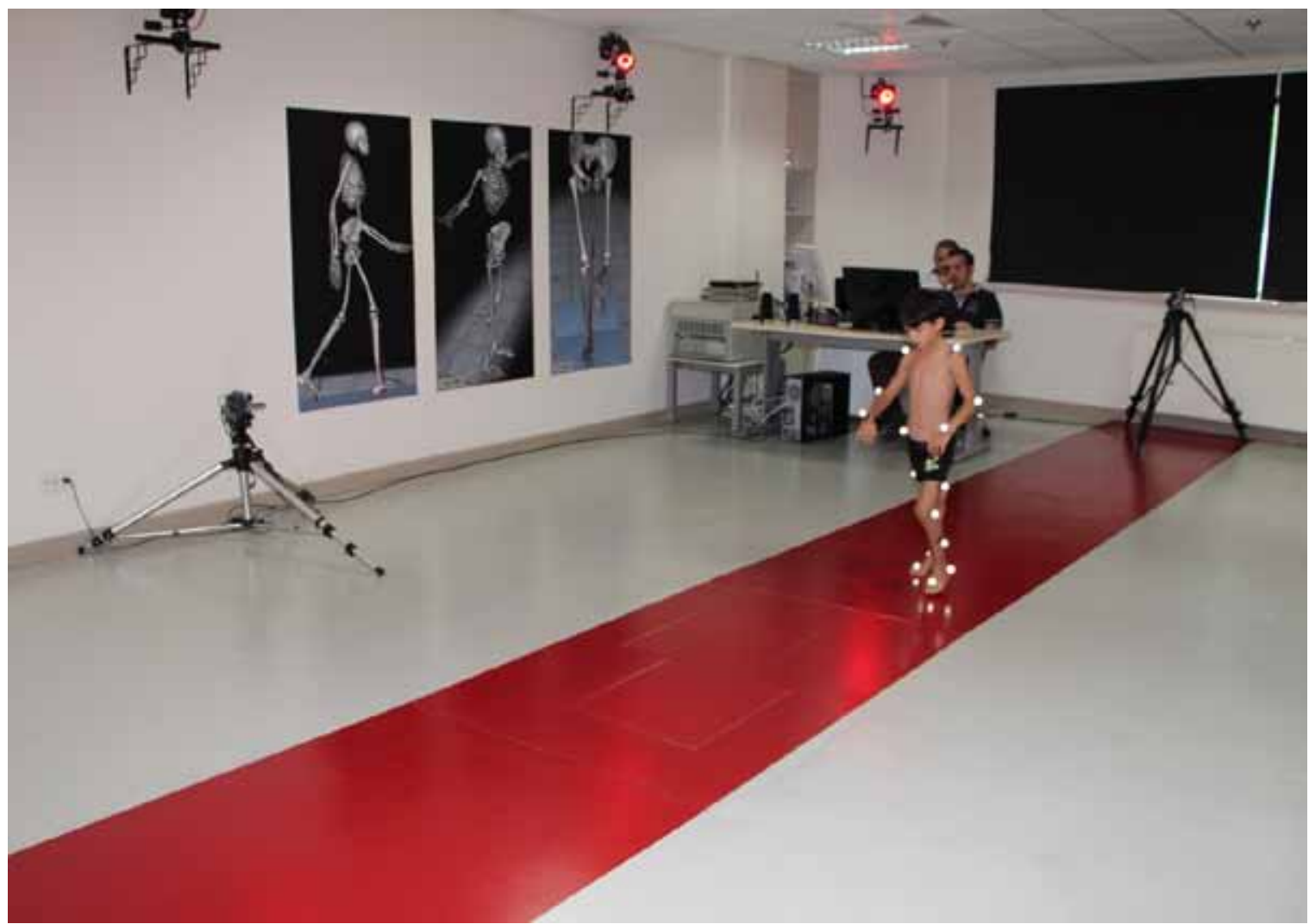

Şekil 3. Yürüme analizi platformu. 
orta noktasına; 20. ve 21. marker, lateral malleol orta noktasına; 22. ve 23. marker, posteriorda kalkaneus ortasına; 24. ve 25. marker, 2. ve 3. ayak parmağı orta noktasına; 26 . ve 27 . marker, mediyalde diz orta noktasına; 28. ve 29. marker, mediyal malleol tepe noktasına) hastanın cildine retroreflektif işaretleyici olarak yerleştirilir (Şekil 4).
Vücuduna işaret cihazları (29 adet marker - işaretleyici) yerleştirilen model sisteme tanıtılır, kişi kameraların görüş alanındaki önceden belirlenmiş ve ortasında kuvvet platformu olan 5-6 metrelik bir yol boyunca yürütülür. Bu cihazlardan gelen sinyaller yüksek hızlı (saniyede 120 resim alabilen) özel kameralar aracılığıyla üç boyutlu olarak görüntülenir (Şekil 5). Ayrıca kişinin
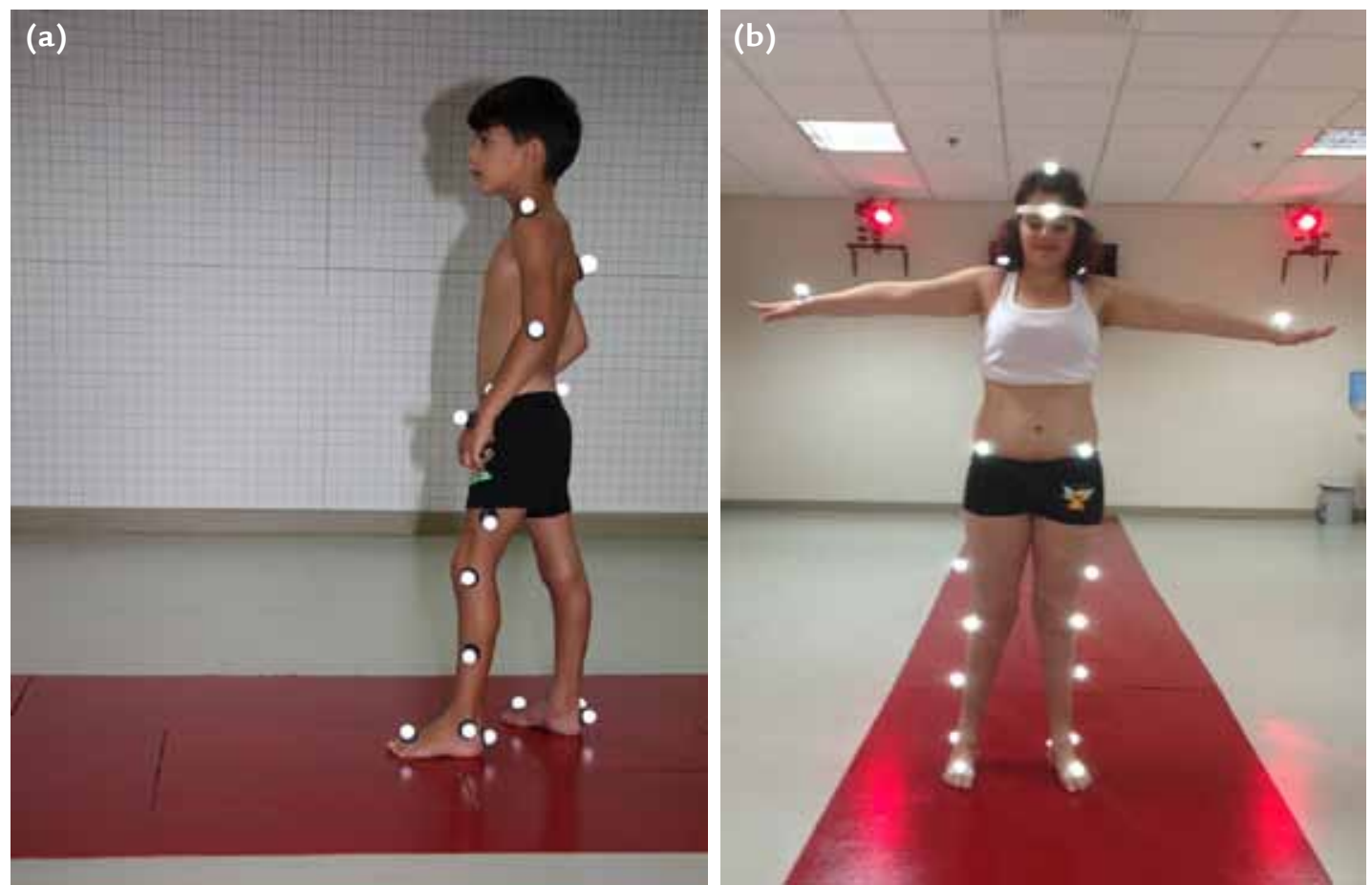

Şekil 4. a, b. İşaretleme sonrasının çocuğun önden (a) ve yandan (b) görünümü.

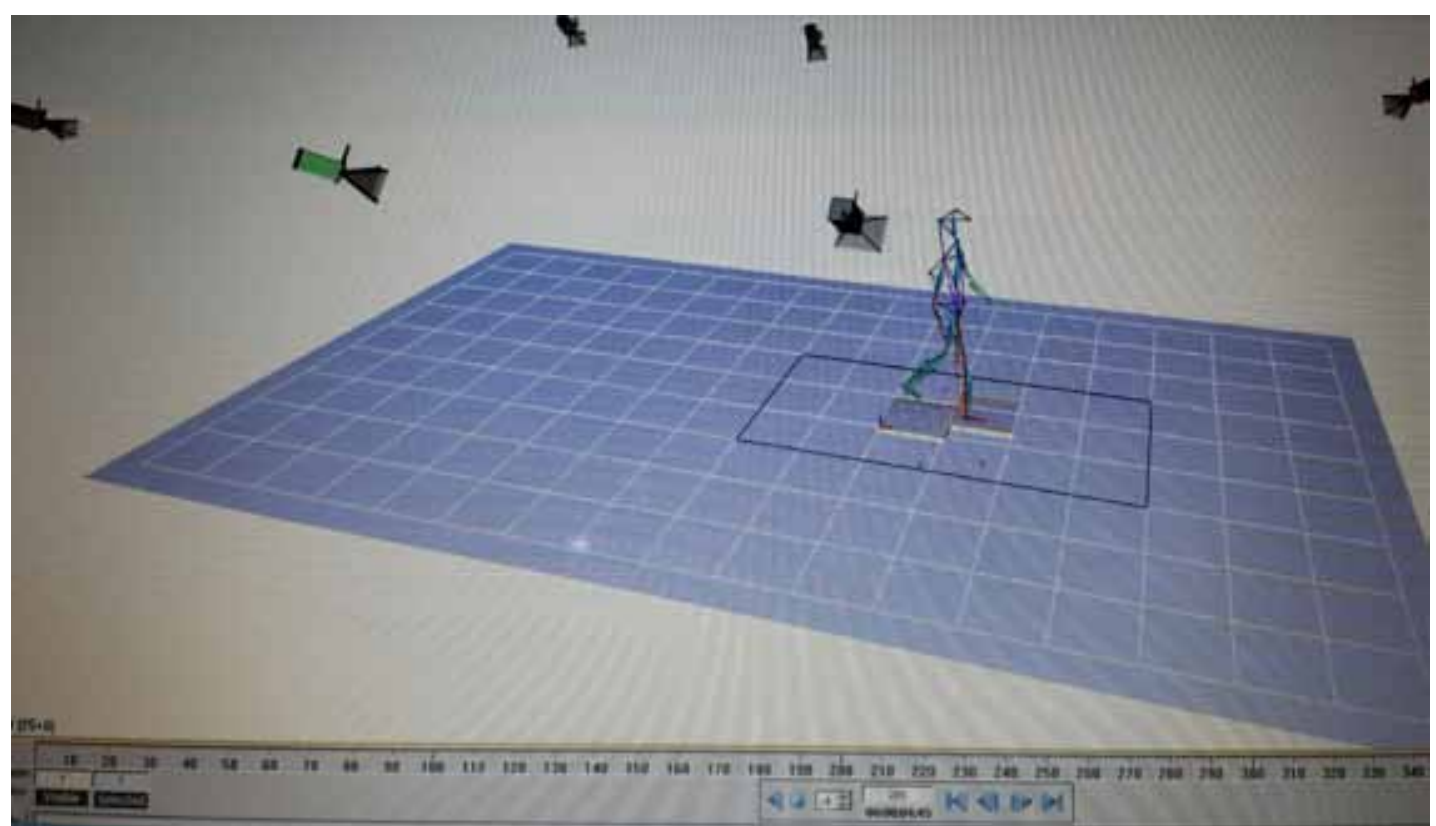

Şekil 5. İşaretleyicilerin bilgisayara tanıtımı sonrasında elde edilen diyagram. 
kuvet platformuna basarak geçtiğinde basma fazında oluşan yer tepki kuvvet vektörleri $20 \mathrm{~ms}$ aralıklarla hesaplanır. Uygun yürüyüşler bilgisayarda geliştirilmiş yazılımlar ile işlenir. Bu işlem sonucunda yürüme siklusu boyunca her eklemin üç hareket planındaki açısal değişimleri hesaplanır. Bir zaman biriminden diğer zaman birimine olan yer değişiminden hız, hız değişiminden ise ivme hesaplanabilir. ${ }^{[1,8,9]}$ Sonuçta tüm bu işlemler sonucu (kinematik ve kinetik analiz sonucunda oluşan) frontal-sagittal ve transvers düzlemlerde vücut segmentlerinin grafiksel olarak değerleri elde edilir. ${ }^{[1,10-12]}$

\section{KAYNAKLAR}

1. Yalçın S, Özaras N. Yürüme Analizi. İstanbul: Avrupa Matbaacılık; 2001.

2. Perry J. Gait Analysis: Normal and Pathological Function. Thorofare NJ: SLACK Incorporated; 1992.

3. Barr AE. Biomechanics and Gait. In: Orthopaedic Knowledge Update 7; p.31-7.

4. Gage JR, Deluca PA, Renshaw TS. Gait analysis: principles and applications with emphasis on its use in cerebral palsy. Instr Course Lect 1996;45:491-507.
5. Biomechanics and Gait. Orthopaedic Knowledge Update 6; 2001. p.37-43.

6. Kay RM, Dennis S, Rethlefsen S, Reynolds RA, Skaggs DL, Tolo VT. The effect of preoperative gait analysis on orthopaedic decision making. Clin Orthop Relat Res 2000;(372):217-22.

7. Simon SR. Quantification of human motion: gait analysisbenefits and limitations to its application to clinical problems. J Biomech 2004;37(12):1869-80.

8. Whittle MW. Gait Analysis. An Introduction. Oxford: Butterworth Heinemann; 2002.

9. Pease WS, Quesada PM. Kinematics and kinetics of gait. In: Braddom RL, editor. Physical Medicine and Rehabilitation. Philadelphia: WB Saunders; 1996 p.83-103.

10. Gage JR. The clinical use of kinetics for the evaluation of pathologic gait in cerebral palsy. Instr Course Lect 1995;44:507-15.

11. Schwartz M. Kinematics of normal gait. In: Gage JR, editor. Treatment of Gait Problems in Cerebral Palsy. London: McKeith Press; 2004. p.99-119.

12. Davis RB, Qunpuu S. Kinetics of Normal Gait. In: Gage JR, editor. Treatment of Gait Problems in Cerebral Palsy. London: McKeith Press; 2004. p.120-33. 